\title{
Itinerário de Concepção Curricular para Curso Técnico em Informática sob a Perspectiva da Indissociabilidade e Interdisciplinaridade
}

\author{
Bruno Costa, Alberto Filho, Caio lamas, Ely Severiano, Igor Ribeiro, \\ Leonardo Nardi, Marcel Amorim, Patricia Grasel, Rafael Costa, \\ Roni Ferreira, Werusca Pinto
}

Curso Técnico em Informática para Internet - Instituto Federal de Educação, Ciência e Tecnologia do Rio de Janeiro (IFRJ) - São João de Meriti - Brasil

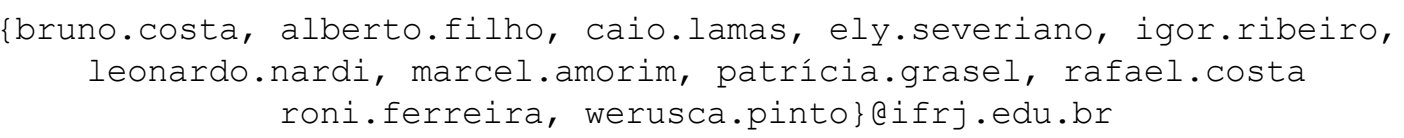

Abstract. The central issue in the curriculum development process is to identify which knowledge is considered important, valid or essential to be considered part of the curriculum. Considering the areas of Informatics and Computing, curriculum development proves to be even more challenging. Since the advent and substantial development of these areas occurred effectively in the twentieth and twenty-first centuries, there is no multi-century maturity. In this sense, the purpose of this article is to present a report about the curricular conception of the Technical Course on Internet Informatics of the Federal Institute of Education, Science and Technology of Rio de Janeiro (IFRJ) considering inseparability and interdisciplinarity.

Resumo. A questão central do processo de desenvolvimento curricular consiste em identificar quais saberes ou conhecimentos são considerados importantes, válidos ou essenciais para merecerem ser considerados parte do currículo. Tendo em vista as áreas de Informática e Computação, o desenvolvimento curricular se mostra ainda mais desafiador. Como o advento $e$ desenvolvimento substancial dessas áreas ocorreu efetivamente nos séculos XX e XXI, não há uma maturidade multi centenária. Neste sentido, o objetivo deste artigo é apresentar um relato acerca da concepção curricular do Curso Técnico em Informática para Internet do Instituto Federal de Educação, Ciência e Tecnologia do Rio de Janeiro (IFRJ), considerando a indissociabilidade e interdisciplinaridade.

\section{Introdução}

Proveniente do étimo latino currere, que significa "caminho", "jornada", "percurso a seguir", o termo currículo encerra, segundo pensamentos convergentes de diferentes autores(as), em uma concepção pedagógica, a qual dirige a ação docente com base na estrutura e organização de conteúdos, visando experiências de aprendizagem em busca da formação ideal do educando (VARELA, 2013). Nesse sentido, a questão central do processo de desenvolvimento curricular consiste em identificar quais saberes ou conhecimentos são considerados importantes, válidos ou essenciais para merecerem ser 
considerados parte do currículo. Pela sua natureza, o desenvolvimento curricular é uma tarefa complexa, que leva em consideração diversos aspectos, dentre eles, objetivos gerais e específicos previamente definidos, o universo cultural, as necessidades e motivações dos educandos, a articulação vertical (ou sequência diacrônica), a articulação horizontal (ou integração disciplinar) e a exequibilidade, inerente aos contextos e às condições de ensino-aprendizagem. Considerando as áreas de Informática e Computação, o desenvolvimento curricular se mostra ainda mais desafiador, pois como o advento e o desenvolvimento substancial dessas áreas ocorreu efetivamente a partir do final do século XX, consideramos que as reflexões acerca deste desenvolvimento estão em processo de maturação.

O objetivo deste artigo é apresentar um relato acerca da concepção curricular do Curso Técnico em Informática para Internet do Instituto Federal de Educação, Ciência e Tecnologia do Rio de Janeiro (IFRJ), cujo a carga horária é de 1.000 horas, dividida em 3 semestres letivos.

Na próxima seção, apresentamos o referencial teórico utilizado na reformulação curricular. Em seguida, na Seção 3 descrevemos o processo utilizado, suas principais fases e resultados intermediários. Por fim, na Seção 4, as considerações finais.

\section{Referencial Teórico}

\subsection{Projeto Integrador}

Um Projeto Integrador representa uma proposta pedagógica transversal que perpassa os três períodos letivos do curso, em que a aprendizagem construída pelo discente é baseada na resolução de problemas. Esta concepção pedagógica busca, à luz da teoria de Bender (2015), definir-se como uma metodologia de ensino ativa, já que trata de ações pedagógicas que proporcionem aos discentes o foco no aprendizado, oferecendo instrumentos para que ele aprenda a aprender; os discentes são sujeitos ativos no processo de ensino e aprendizagem, pois tem como princípio é pedagogia interativa.

\subsection{Desenvolvimento curricular}

De acordo com Gaspar e Roldão (2014), existem três fases clássicas no desenvolvimento curricular, a saber: concepção, implementação e avaliação. Neste relato, destacamos as atividades realizadas na fase de concepção, entendida como o processo de tomada de decisões conformadoras do currículo. Nos baseamos no modelo de Tyler (1950), uma das referências mais utilizadas no ocidente para o desenho de currículos (LOPES, 2014).

O modelo de Tyler prevê quatro etapas da concepção curricular: (i) a formulação de objetivos ou fins que o curso deve alcançar; (ii) a seleção de experiências educativas que permitem a interação entre o discente e as condições externas; (iii) a organização das experiências de aprendizagem, ou seja, a seleção das atividades, organizadas em ementas e programas de ensino organizados de forma vertical (segundo critérios de continuidade e sequenciação) e horizontal (segundo o critério da integração), e; (iv) a avaliação da eficácia das atividades de aprendizagem, mediante o confronto dos resultados com os objetivos definidos na primeira fase. Sobre esta etapa, o modelo tem por objetivo responder a quatro perguntas básicas: 
VIII Congresso Brasileiro de Informática na Educação (CBIE 2019)

Anais dos Workshops do VIII Congresso Brasileiro de Informática na Educação (WCBIE 2019)

1. Que objetivos educacionais deve o curso procurar atingir?

2. Que experiências educacionais podem ser oferecidas que possibilitem a consecução desses objetivos?

3. Como podem essas experiências educacionais serem organizadas de modo eficiente?

4. Como podemos determinar os objetivos educacionais estão sendo alcançados?

\section{Concepção do currículo do Curso Técnico em Informática para Internet do IFRJ}

Os cursos de Educação Profissional Técnica de Nível Médio têm por finalidade proporcionar ao estudante conhecimentos, saberes e competências profissionais necessários ao exercício profissional e da cidadania, com base nos fundamentos científico-tecnológicos, sócio-históricos e culturais (MEC, 2012). Além disso, são princípios norteadores desta modalidade de educação, dentre outros, a indissociabilidade entre educação e prática social, considerando-se a historicidade dos conhecimentos e dos sujeitos da aprendizagem; a indissociabilidade entre teoria e prática no processo de ensino-aprendizagem, e; a interdisciplinaridade assegurada no currículo e na prática pedagógica, visando à superação da fragmentação de conhecimentos e de segmentação da organização curricular. Indissociabilidade (entre educação prática e social, e entre teoria e prática) e interdisciplinaridade foram os dois princípios fundamentais que nortearam o processo de concepção curricular do Curso Técnico em Informática para Internet do IFRJ.

Os trabalhos foram realizados entre os meses de março e novembro de 2018. Fizeram parte da equipe os autores deste artigo. A Tabela 1 apresenta a área de especialidade e o quantitativo dos membros responsáveis pelo desenvolvimento curricular, sendo possível identificar o caráter multidisciplinar da equipe.

Tabela 1 - Perfil e quantitativo dos responsáveis pela concepção curricular

\begin{tabular}{|l|c|}
\hline \multicolumn{1}{|c|}{ Área } & Quantitativo \\
\hline Programação de Computadores e Engenharia de Software & 4 \\
\hline $\begin{array}{l}\text { Arquitetura de Computadores; Sistemas Operacionais, Manutenção } \\
\text { de Hardware; Redes de Computadores e Gerenciamento de Serviços } \\
\text { de Tecnologia da Informação }\end{array}$ & 3 \\
\hline Pedagogia & 1 \\
\hline Linguagens e Humanidades & 3 \\
\hline
\end{tabular}

Foram realizadas 10 reuniões, intermediadas com trabalhos coordenados por membros das respectivas áreas. Na primeira reunião foi apresentada a proposta de concepção curricular, assim como a metodologia adotada. Nesta reunião também foram identificados as áreas dos professores, dividindo-os nas respectivas equipes. Como tarefa para a segunda reunião, as equipes deveriam trazer sugestões para a elaboração dos objetivos do curso. 
VIII Congresso Brasileiro de Informática na Educação (CBIE 2019)

Anais dos Workshops do VIII Congresso Brasileiro de Informática na Educação (WCBIE 2019)

\subsection{Objetivos educacionais}

Seguindo o modelo de Tyler, a primeira pergunta do processo de desenvolvimento curricular foi respondida na segunda reunião, a saber,

O Curso Técnico em Informática para Internet do IFRJ tem como objetivo geral formar técnicos aptos ao desenvolvimento de soluções computacionais para as demandas da sociedade e do mercado, de forma integrada à análise crítica da realidade histórico-social.

Este objetivo geral foi detalhado em oito objetivos específicos, sendo eles,

1. Capacitar os educandos na criação de páginas de internet (programação Front-End), aplicando boas práticas e padrões de acessibilidade;

2. Capacitar os educandos na criação de componentes que dão suporte às páginas de internet (programação Back-End), aplicando boas práticas e padrões de projeto;

3. Desenvolver a visão sistêmica e colaborativa de uma solução compreendendo as programações Front-End e Back-End (programação Full-Stack);

4. Capacitar os educandos na identificação dos principais componentes de hardware de um computador;

5. Capacitar os educandos no projeto e suporte de redes de computadores;

6. Projetar, desenvolver e implantar soluções computacionais envolvendo hardware e software, de forma articulada;

7. Desenvolver saberes da língua inglesa necessários ao projeto, desenvolvimento e implantação de soluções computacionais;

8. Proporcionar itinerários formativos que permitam aos educados o posicionamento ético, social e reflexivo sobre o impacto de suas práticas na sociedade.

Através destes objetivos, abarcou-se o princípio norteador da indissociabilidade. Em especial, o oitavo objetivo específico define que a organização curricular deverá contemplar aspectos sociais, a fim de proporcionar uma formação integral ao educando.

\subsection{Seleção de experiências educativas}

A segunda fase do desenvolvimento curricular se iniciou na segunda reunião, após a deliberação dos objetivos. A identificação das disciplinas que iriam compor a matriz curricular do curso foi elaborada de forma paralela, pelos professores das respectivas áreas de especialidade. $\mathrm{O}$ trabalho foi coordenado por cada responsável de área e auxiliado por um pedagogo.

Nesta seleção, foram elencados elementos formativos que promoviam aspectos como inserção, reinserção e qualificação dos educandos para o mercado de trabalho, de forma que seja possível desenvolver suas habilidades, capacitando-os com conhecimentos teóricos e práticos. Neste momento, os professores não conceberam o programa de ensino detalhado das disciplinas, apenas o nome, ementa e carga-horária. 
Nas três reuniões seguintes, foram apresentadas as disciplinas por área, por meio de discussões cujo objetivo foi identificar elementos que promoviam a interdisciplinaridade. Algumas disciplinas mudaram de nome e/ou tiveram suas ementas alteradas de forma a facilitar ao educando a identificação de correlação entre elas. Após estas reuniões, com a seleção das experiências educativas concluída, a segunda pergunta do modelo de Tyler foi respondida.

\subsection{Organização das experiências de aprendizagem}

Após a quinta reunião, com as disciplinas selecionadas, os professores deveriam analisar e propor formas de organização que favorecessem a interdisciplinaridade a indissociabilidade entre teoria e prática; os dois encontros seguintes foram marcados por um intenso e fecundo debate pedagógico. A conclusão foi a de que a interdisciplinaridade devia estar inicialmente circunscritas ao âmbito de cada área, isto é, deveriam ser articuladas experiências de aprendizagem mais próximas ao seu objeto de conhecimento. Assim, foram divididas as três grandes áreas da organização curricular, a saber,

1. Desenvolvimento

2. Infraestrutura e Serviços

3. Linguagens e Humanidades

$\mathrm{Na}$ divisão das áreas de desenvolvimento e infraestrutura e serviços (áreas específicas), os professores utilizaram documentos de referência para cursos de graduação em computação (ZORZO et al., 2017). A organização de disciplinas por áreas favoreceu o diálogo entre os professores de uma mesma área, os quais também reviram os títulos e ementas das disciplinas de forma a favorecer a interdisciplinaridade. Por fim, a divisão da carga horária resultou nos percentuais demonstrados na Figura 1.

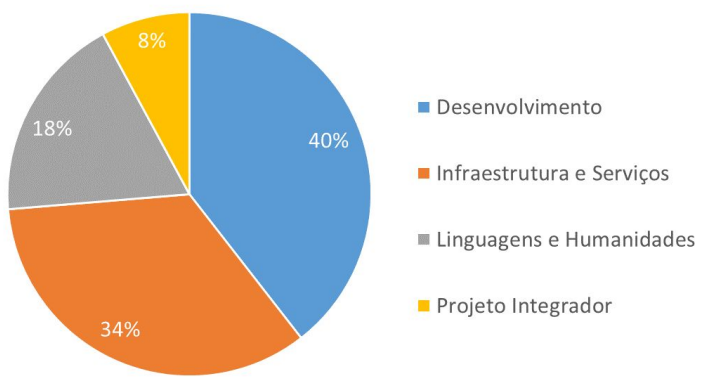

Figura 1. Distribuição da Carga Horária do Curso

Além da carga-horária destinada às disciplinas relacionadas às grandes áreas do curso, verifica-se que $8 \%$ da carga-horária foi destinada ao Projeto Integrador, o qual aconteceria dois momentos. O primeiro corresponde ao desenvolvimento de um projeto no decorrer do curso (apresentado na próxima seção), com participação de todas as disciplinas do curso; o segundo, desenvolveria-se no contexto de uma disciplina específica, no último período do curso, na qual os educandos iriam desenvolver um projeto em uma das duas áreas específicas, desenvolvimento ou infraestrutura e serviços, sob a orientação de um professor. 
$\mathrm{Na}$ oitava e nona reuniões foram realizadas discussões sobre estratégias para aprofundar a interdisciplinaridade. Neste sentido foi estabelecido que os programas de ensino seriam definidos no ano seguinte, durante o qual os professores desenvolveriam o Projeto Integrador, identificando os conteúdos que detalhariam a ementa e comporiam o desenvolvimento metodológico das disciplinas. Esta abordagem se mostrou exitosa, tendo em vista que os conteúdos seriam selecionados com base em um projeto desenvolvido, facilitando a identificação dos elementos formativos necessários a constar nas disciplinas.

No momento em que este artigo está sendo escrito, os professores estão desenvolvendo este projeto, que conterá diretrizes para os conteúdos que devem ser abordados nas disciplinas.

\subsection{Projeto Integrador}

O Projeto Integrador a ser desenvolvido no decorrer do curso foi organizado em três etapas, de acordo com os períodos do curso e disciplinas, conforme detalhamento a seguir:

- $1^{\circ}$ período - modelagem e implementação inicial de um sistema de software e configuração da infraestrutura subjacente, articulado nas disciplinas: Algoritmos e Programação de Computadores com o Paradigma Imperativo, Modelagem de Domínio e Conceitos de Orientação à Objetos, Organização de Computadores e Redes de Computadores I;

- $2^{\circ}$ período - conclusão da primeira versão do sistema e sua implantação em infraestrutura subjacente, articulado nas disciplinas Programação Front-End I, Programação Back-End I, Projeto e Implementação de Bancos de Dados, Redes de Computadores II e Infraestrutura para Serviços de Internet

- $3^{\circ}$ período - aprimoramento do sistema de software desenvolvido nos períodos anteriores e disponibilização de acesso ao sistema pela internet, com culminância nas disciplinas Programação Front-End II, Programação Back-End II, Redes de Computadores III e Gerenciamento de Serviços de Tecnologia da Informação.

Com base nos conhecimentos e habilidades adquiridas no desenvolvimento do Projeto Integrador, no último período do curso será proposto aos discentes o desenvolvimento de um projeto final na disciplina Empreendedorismo e Projeto Final. Neste projeto, o educando poderá escolher uma área, desenvolvimento ou infraestrutura, e contará com o auxílio do professor da disciplina no decorrer do semestre. 
VIII Congresso Brasileiro de Informática na Educação (CBIE 2019)

Anais dos Workshops do VIII Congresso Brasileiro de Informática na Educação (WCBIE 2019)

\subsection{Matriz Curricular do Curso Técnico em Informática para Internet}

A Figura 2 apresenta a matriz curricular do Curso Técnico em Informática para Internet.

\begin{tabular}{|c|c|}
\hline \multicolumn{2}{|r|}{$1^{\circ}$ Período } \\
\hline Área & Disciplina \\
\hline \multirow{2}{*}{ Desenvolvimento } & Algoritmos e Programação de Computadores \\
\hline & Modelagem de Domínio e Conceitos de Orientação à Objetos \\
\hline \multirow{2}{*}{ Infraestrutura e Serviços } & Organização de Computadores \\
\hline & Redes de Computadores I \\
\hline \multirow{2}{*}{ Linguagens e Humanidades } & Metodologia e Produção de Conhecimento na Cultura Digital \\
\hline & Ética na Informática \\
\hline \multicolumn{2}{|r|}{$2^{\circ}$ Período } \\
\hline \multirow{3}{*}{ Desenvolvimento } & Programação Front-End I \\
\hline & Programação Back-End I \\
\hline & Projeto e Implementação de Bancos de Dados \\
\hline \multirow{2}{*}{ Infraestrutura e Serviços } & Redes de Computadores II \\
\hline & Infraestrutura para Serviços de Internet \\
\hline Linguagens e Humanidades & Inglês para Fins Específicos I \\
\hline \multicolumn{2}{|r|}{$3^{\circ}$ Período } \\
\hline \multirow{2}{*}{ Desenvolvimento } & Programação Front-End II \\
\hline & Programação Back-End II \\
\hline \multirow{2}{*}{ Infraestrutura e Serviços } & Redes de Computadores III \\
\hline & Gerenciamento de Serviços de Tecnologia da Informação \\
\hline \multirow{2}{*}{ Linguagens e Humanidades } & Sociologia da Informação \\
\hline & Inglês para Fins Especificos II \\
\hline Projeto & Empreendedorismo e Projeto Final \\
\hline
\end{tabular}

Figura 2. Matriz Curricular do Curso Técnico em Informática para Internet

\section{Considerações Finais}

A reestruturação curricular do Curso Técnico em Informática para Internet possibilitou a qualificação da concepção de currículo. As etapas de desenvolvimento do projeto pedagógico serviram para repensar as práticas docentes e as competências específicas e humanas que o mercado exige, assim como as estratégias de ensino e aprendizagem de conteúdos. Além, possibilitou aos a oportunidade de refletir dialogicamente tanto sobre elementos que têm apresentado resultados positivos, quanto acerca dos que fragilizam as práticas docentes e discentes.

O momento da concepção das ementas, algumas reelaboradas, possibilitou a revisão de conceitos sobre o profissional que deve ser "entregue" ao mercado e sobre as responsabilidades do curso e de seus docentes sobre as demandas dos discentes em relação à sociedade atual. Foi um período de reconhecer novas práticas de ensino e aprendizagem, conjugando competências para a empregabilidade a partir de princípios de cidadania.

A revisão de uma matriz curricular de forma coletiva, através de uma gestão participativa e com etapas formativas, contribuem significativamente para que os docentes compreendam a concepção pedagógica que precisa emergir em suas práticas. 
Esta metodologia de trabalho busca minimizar equívocos de compreensão do currículo, já que convida os docentes para serem autores do documento integral, e contribui para uma formação holística do educando, uma vez que pretende romper com a dicotomização do conhecimento científico.

\section{Referências}

BENDER, W. N.. Aprendizagem baseada em projetos: educação diferenciada para o Século XXI. Porto Alegre, RS: Penso, 2015

GASPAR, I.; ROLDÃO, M. DO C. Elementos do Desenvolvimento Curricular. Lisboa: Universidade Aberta, 2014.

LOPES, A. C. Teorias de Currículo. São Paulo: Cortez, 2014.

MEC. Resolução CNE/CEB 6 /2012. Brasília: Diário Oficial da União, 2012.

MEC. Catálogo Nacional de Cursos Técnicos. 3. ed. Brasília/DF: Secretaria de Educação Profissional e Tecnológica, 2014.

TYLER, R. W. Basic Principles of Curriculum and Instruction. [s.l.] University of Chicago Press, 1950.

VARELA, B. L. O Currículo e o Desenvolvimento Curricular: Concepções, Práxis, Tendências. Cabo Verde, República de Cabo Verde: Edições UNIVCV, 2013.

ZORZO, A. F. et al. Referenciais de Formação para os Cursos de Graduação em Computação 2017. [s.l.] Sociedade Brasileira de Computação (SBC), 2017. 